\title{
Bed capacities and disinfection practices in hospitals in Istanbul are correlated
}

\author{
Bahri Teker ${ }^{1}$, Aziz Ogutlu ${ }^{2,5^{*}}$, Mesut Yilmaz ${ }^{3}$, Serap Gencer ${ }^{4}$ and Oguz Karabay ${ }^{2,5}$
}

\begin{abstract}
Background: Disinfection, antisepsis and sterilization (DAS) practices are of critical importance in hospital practice. This study aims to investigate the daily DAS practices of private hospitals in Istanbul, Turkey.

Methods: The DAS practices of 155 private hospitals in Istanbul province were investigated using a questionnaire including 26 questions. The questionnaire forms were faxed to all private hospitals located in Istanbul. A $p$ value $<0.05$ accepted as significant.

Results: The 75 [48\%] hospitals out of 155 hospitals responded. The quality of DAS practice was correlated with hospital bed capacity. In these hospitals, glutaraldehyde (27\%) was the most common chemical used to disinfect endoscopy instruments. The rate of availability of air gun in endoscopy units in these hospitals was significantly associated with hospital bed capacity $(\mathrm{p}<0.001)$. Sticky mats placed at doors of risky areas were not reported to be used in the large bed capacity (LBC) hospitals unlike the small bed capacity (SBC) hospitals where 50\% of these hospitals reported to use the sticky door mats ( $p=0.0144)$.
\end{abstract}

Conclusions: Private hospitals in Istanbul need in-service training towards sterilization and disinfection issues. It is concluded that private hospitals need policies and educational activities for DAS practices.

Keywords: Sterilization, Disinfection, Antisepsis, Disinfection error, Private hospital

\section{Introduction}

Most microorganisms capable of nosocomial infections can survive for weeks or even months on patients, healthcare providers, and in the hospital environments [1]. These microorganisms can then spread to other patients from these sources [2].

Most of nosocomial infections can be prevented if the standard infection control precautions are rigorously applied. Sterilization units are of critical importance for sterilization procedures in hospitals and are required to serve in accordance with the established standards. Indeed, achieving and maintaining the required standards is essential for quality of health care since incomplete sterilization and untrained staff can cause nosocomial infections [3].

The standards implemented in the Turkish public and university hospitals are consistent with the minimum

\footnotetext{
* Correspondence: drogutlu@hotmail.com

${ }^{2}$ Department of Clinical Microbiology and Infectious Diseases, Medicine Faculty of Sakarya University, Sakarya, Turkey

${ }^{5}$ Health Science Institute of Sakarya University, Sakarya, Turkey

Full list of author information is available at the end of the article
}

disinfection, antisepsis and sterilization [DAS] requirements accepted worldwide [4]. However, we could not achieve any data indicating to what extent the DAS standards are being implemented in the private hospitals serving thousands of people every day in Istanbul where approximately 14 million people live. With this study, investigation of some of the key indicators regarding DAS practices were aimed for the first time reaching 155 private hospital serving in Istanbul.

\section{Materials and methods \\ Survey}

A survey consisting of 26 multiple-choice questions and investigating the hospitals' DAS practice was prepared for each private hospital (Additional file "1", questionnaire form). This survey has been sent to managing directors of all the private hospitals through the Istanbul Provincial Directorate of Health. People who were identified by the Infection Control Committees in the private hospitals were asked to respond to the survey questions.

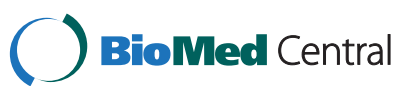

(c) 2015 Teker et al.; licensee BioMed Central. This is an Open Access article distributed under the terms of the Creative Commons Attribution License (http://creativecommons.org/licenses/by/4.0), which permits unrestricted use, distribution, and reproduction in any medium, provided the original work is properly credited. The Creative Commons Public Domain Dedication waiver (http://creativecommons.org/publicdomain/zero/1.0/) applies to the data made available in this article, unless otherwise stated. 


\section{Following guideline}

We compared the hospitals practices with national DAS guideline [5].

\section{Hospitals}

There were 155 private hospitals in Istanbul at the date of this study. 56 private (36.1\%) hospitals answered the survey in the first place. Upon sending a reminder to the hospitals which did not respond, 19 (12.3\%) more hospitals answered and responded to the survey. As a result, the results of the 75 hospitals (48.4\%) responded were evaluated.

\section{Statistical analysis}

The data was recorded in MS Excel format. The data were analyzed using EPI Info ver. 6.0 [CDC, AtlantaUSA] program. Chi-square test and Fisher's exact test were used for statistical significance. $\mathrm{P}<0.05$ was considered to be significant.

\section{Results}

Seventy five (48.4\%) of 155 hospitals responded to the survey. When bed capacities of the 75 hospital responding to this study are evaluated, it is seen that 26 hospitals (34.7\%) have a capacity under 50 beds (small capacity, SC) and 41 hospitals (54.7\%) have a capacity of 50 beds and above (Large capacity, LC). No information about the bed capacity of 8 hospitals $(10.7 \%)$ was available. It was observed that the hospitals with LC used alternative methods in some implementations of DAS practices (Table 1).

While 23 (31\%) of the hospitals used alcohol-based antiseptics for hand hygiene alone, 11 of the hospitals (15\%) used alcohol with other compounds methods. The remaining 34 hospitals (45\%) used soap and alcoholbased hand antiseptics together.

The types of chemicals used to disinfect endoscopy instruments in these hospitals were as follows; 20 hospitals $(27 \%)$ glutaraldehyde, 6 hospitals (8\%) Orthophthalaldehyde [OPA], 22 hospitals (29\%) peracetic acid, 6 hospitals (8\%) hydrogen peroxide, 6 hospitals (8\%) quaternary ammonium, 16 hospitals $(21 \%)$ another (quaternaryammonium + biguanide, glutaraldehyde + phenol/phenate, $\mathrm{H}_{2} \mathrm{O}_{2}+$ peracetic asid) disinfectant.

The following chemicals were reportedly used to disinfect floors and surfaces of the intensive care units; 29 hospitals (39\%) bleach or chlorine tablets, 3 hospitals (4\%) phenol compound, 11 hospitals (15\%) quaternary ammonium, 1 hospital (1\%) solution containing formaldehyde, 24 hospitals (32\%) didecyl dimethyl ammonium chloride, 22 hospitals (29\%) mixtures of these compounds.

And the chemicals used to disinfect floors and surfaces of the operating rooms were; 23 hospitals (31\%) bleach or chlorine tablets, 3 hospitals (4\%) phenol compound, 11 hospitals (15\%) quaternary ammonium, 2 hospitals (3\%) solutions containing formaldehyde, 23 hospitals (31\%) didecyl dimethyl ammonium chloride, 25 hospitals (33\%) mixtures of these compounds.

72 hospitals (96\%) reported that floors were disinfected in inpatient services. The reported types of disinfectant materials used by the hospitals for this purpose were as follows; 48 hospitals (64\%) bleach or chlorine tablets, 3 hospitals (4\%) phenol compound, 11 hospitals (15\%) quaternary ammonium, 1 hospital (1\%) solutions containing formaldehyde, 18 hospitals $(24 \%)$ didecyl dimethyl ammonium chloride, 20 hospitals (27\%) mixtures of these compounds.

Table 1 Comparing the hospitals based on their bed capacities

\begin{tabular}{|c|c|c|c|c|c|c|c|}
\hline \multirow[t]{2}{*}{ Parameter } & \multicolumn{2}{|c|}{ Large-scale hospital >50 } & \multicolumn{2}{|c|}{ Small-scale hospital $<50$} & \multicolumn{2}{|c|}{ Total* } & \multirow{2}{*}{$\begin{array}{l}\mathrm{P} \text { value } \\
\mathrm{p}\end{array}$} \\
\hline & $n$ & $\%$ & $n$ & $\%$ & $\mathbf{N}$ & $\%$ & \\
\hline Overshoes are worn when entering into intensive care unit & 22 & 54 & 19 & 73 & 43 & 57 & 0.0617 \\
\hline Sticky mats are used & 8 & 20 & 13 & 50 & 24 & 32 & 0.0144 \\
\hline Gas-plasma system is available & 9 & 22 & 1 & 4 & 12 & 16 & 0.0780 \\
\hline Central sterilization unit (CSU) is available & 34 & 83 & 16 & 62 & 57 & 76 & 0.0823 \\
\hline A physician responsible for $\mathrm{CSU}$ is available & 15 & 37 & 8 & 31 & 25 & 33 & 0.5958 \\
\hline Sterilization records can be accessed retrospectively & 39 & 95 & 25 & 96 & 72 & 96 & 1.0000 \\
\hline Air gun is used in washing unit & 31 & 76 & 8 & 31 & 45 & 60 & 0.0003 \\
\hline Ethylene oxide sterilizer is available & 13 & 32 & 40 & 15 & 18 & 24 & 0.1555 \\
\hline Automatized endoscope washer in operating room is available & 19 & 46 & 7 & 27 & 30 & 40 & 0.1245 \\
\hline Endoscopy unit is available in hospital & 39 & 95 & 17 & 65 & 60 & 80 & 0.0022 \\
\hline Automatized endoscope washer is available in endoscopy unit & 20 & 49 & 8 & 31 & 31 & 41 & 0.5914 \\
\hline At least one of the autoclaves is older than 10 years & 13 & 32 & 0 & 0 & 14 & 19 & 0.0009 \\
\hline Ground disinfectant is used in inpatient services & 40 & 98 & 24 & 92 & 72 & 96 & 0.5550 \\
\hline
\end{tabular}

*No data about the bed capacity of 8 hospitals (10.7\%) was available. 


\section{Discussion}

In this study we examined disinfection and sterilization practices of 75 private hospitals in Istanbul. Interestingly, we observed that the most widely used disinfectant for endoscopy instruments was glutaraldehyde (27\%), which may be attributed to economic reasons. OPA is 7 to 10 times more expensive than gluteraldehyde. It is essential that environments where glutaraldehyde is applied should be well ventilated because of its potentially toxic vapor to human body. Use of this product by hospitals without adequate ventilation threatens the staff health. Another reason why this chemical is widely used may be due to the fact that it has been used in hospitals for ages and well known by health care providers. If private hospital administrators are trained about existence and advantages of alternative products, preferences of private hospitals for endoscopy disinfection may change. Also, the endoscope manufacturers recommend use of glutaraldehyde as disinfectant among others $[6,7]$.

The most widely used chemical in high risk contamination areas, such as operating rooms and intensive care units, was bleach (39\%). This is the practice proposed in many countries and a relatively a cheaper alternative. Remarkably, most of the hospitals responded to the survey $(61 \%)$ do not use bleach. This may be due to the effect of bleach resulting smell and headaches $[8,9]$.

The use of quaternary ammonium (15\%) in the intensive care units is thought provoking. It should be noted that quaternary ammonium compounds are bacteriostatic and are ineffective to Hepatitis B and Pseudomonas aeruginosa [10].

Although it is enough to clean the inpatient services of the hospitals just with water and detergent -except high risk areas and fomites (surfaces frequently touched by hands such as door handles, bed-heads and bedside cabinets, tap handles etc.), the hospitals use $4 \%$ phenol compound, $14 \%$ quaternary ammonium chloride, $24 \%$ didecyl dimethyl ammonium chloride. This may be due to a lack of knowledge on the DAS practice [11].

When the use of sticky door mats in the intensive care units was examined, it was observed that private hospitals with small-bed capacity ( $<50$ beds) significantly preferred this method. However, the use of sticky doormats before entering into the high risk areas is not recommended except for controlling dust [12]. The fact that the average rate for wearing overshoes when entering into the intensive care units is $57 \%$ indicates that the guidelines are not adequately observed [12]. This may be due to employment of an Infectious Diseases and Clinical Microbiology Specialist by the hospitals and presence of effective Infection Control Committee established by these hospitals. In addition, we think that this situation may arise when the training for infection control in the hospitals are insufficient.
The use of air gun in the washing units was found to be significantly higher in the LBC hospitals $(p=0.0003)$. The fact that SBC hospitals do not allocate additional resources for washing guns may be due to financial concerns.

The correct sterilization technics of health procedures, invasive implements, materials and equipment used in direct patient care and surgery directly influences patient care. Our study showed that some may be some overlaps. To prevent this purpose it is important that controls raising the required too. These controls should be in the form of both internal and external control. External control official authority should be involved.

\section{Conclusion}

We conclude that private hospitals in Istanbul need inservice training DAS issues. It is also concluded that private hospitals in Istanbul need policies that will standardize the DAS practices and DAS training.

\section{Additional file}

Additional file 1: Questionnaire.

\section{Competing interests}

The authors declare that they have no competing interests.

\section{Authors' contributions}

$\mathrm{BT}, \mathrm{AO}$ and $\mathrm{OK}$ designed the study, prepared the literature, analyzed and interpreted the data, and wrote the manuscript; BT, SG and MY collected the data. All authors read and approved the final manuscript.

\section{Acknowledgement}

This study was presented as EKMUD 2013 congress, Antalya-Turkey.

\section{Author details}

${ }^{1}$ Department of Clinical Microbiology and Infectious Diseases, Private Nisa Hospital, Istanbul, Turkey. ${ }^{2}$ Department of Clinical Microbiology and Infectious Diseases, Medicine Faculty of Sakarya University, Sakarya, Turkey. ${ }^{3}$ Department of Clinical Microbiology and Infectious Diseases, Medicine Faculty of Medipol University, Istanbul, Turkey. ${ }^{4}$ Department of Clinical Microbiology and Infectious Diseases, Kartal Dr. Lutfi Kirdar Education and Research Hospital, Istanbul, Turkey. ${ }^{5}$ Health Science Institute of Sakarya University, Sakarya, Turkey.

Received: 20 October 2014 Accepted: 5 March 2015

Published online: 19 March 2015

\section{References}

1. Dancer SJ. The role of environmental cleaning in the control of hospitalacquired infection. J Hosp Infect. 2009;73:378-85.

2. Hayden MK, Blom DW, Lyle EA, Moore CG, Weinstein RA. Risk of hand or glove contamination after contact with patients colonized with vancomycin-resistant enterococcus or the colonized patients' environment Infect Control Hosp Epidemiol. 2008;29:149-54.

3. Turkish Court of Accounts Performance audit report: Fight against nosocomial infections. 2007.

4. Hospital Service Quality Standards. Sterilization services. Republic Of Turkey Ministry of Health, Department of Performance Management Quality Improvement. Ankara 2011;131-137.

5. Günaydın M, Perçin D, Esen Ş, Zenciroğlu D, Committee of guideline preparatory. Disinfection, Antisepsis and Sterilization (DAS) guideline. 2014. 
Available at; http://www.das.org.tr/index.php/das-download/category/4-dasrehberler.

6. Rutala WA. APIC guideline for selection and use of disinfectants. Am J Infect Control. 1996;24:313-42.

7. Newman MA, Kachuba JB. Glutaraldehyde: a potential health risk to nurses. Gastroenterol Nurs. 1992;14:296-300.

8. Rutala WA, Weber DJ. Uses of inorganic hypochlorite [bleach] in health-care facilities. Clin Microbiol Rev. 1997;10:597-610.

9. Rutala WA, Cole EC, Thomann CA, Weber DJ. Stability and bactericidal activity of chlorine solutions. Infect Control Hosp Epidemiol. 1998;19:323-7.

10. Boyce JM. Environmental contamination makes an important contribution to hospital infection. J Hosp Infect. 2007;65:50-4.

11. Siegel JD, Rhinehart E, Jackson M, Chiarello L, Health Care Infection Control Practices Advisory Committee. 2007 Guideline for Isolation Precautions: Preventing Transmission of Infectious Agents in Health Care Settings. Am J Infect Control. 2007;35:565-164.

12. Guidelines for Environmental Infection Control in Health-Care Facilities Recommendations of CDC and the Healthcare Infection Control Practices Advisory Committee [HICPAC]. Atlanta, GA: U.S. Department of Health and Human Services Centers for Disease Control and Prevention [CDC]; 2003. 30333

\section{Submit your next manuscript to BioMed Central and take full advantage of:}

- Convenient online submission

- Thorough peer review

- No space constraints or color figure charges

- Immediate publication on acceptance

- Inclusion in PubMed, CAS, Scopus and Google Scholar

- Research which is freely available for redistribution 